\title{
Experimental Investigation and High Resolution Simulator of In-Situ Combustion Processes
}

\author{
Quarterly Report
}

\author{
Start date: January 2005 \\ End date: March 2005 \\ Margot Gerritsen \\ Anthony R. Kovscek \\ April 2005 \\ DE-FC26-03 NT15405
}

\author{
Department of Petroleum Engineering \\ Stanford University \\ Green Earth Sciences Building \\ 367 Panama Street \\ Stanford, CA 94305-2220
}




\section{Disclaimer:}

This report was prepared as an account of work sponsored by an agency of the United States Government. Neither the United States Government nor any agency thereof, nor any of their employees, makes any warranty, express or implied, or assumes any legal liability or responsibility for the accuracy, completeness, or usefulness of any information, apparatus, product, or process disclosed, or represents that its use would not infringe privately owned rights. Reference herein to any specific commercial product, process, or service by trade name, trademark, manufacturer, or otherwise does not necessarily constitute or imply its endorsement, recommendation, or favoring by the United States Government or any agency thereof. The views and opinions of authors expresses herein do no necessarily state or reflect those of the United States Government or any agency thereof.

\section{Abstract}

Accurate simulation of in-situ combustion processes is computationally very challenging because the spatial and temporal scales over which the combustion process takes place are very small. In this sixth quarter of our DoE funded research, we continued the development of our new simulation tool which is based on an efficient Cartesian Adaptive Mesh Refinement technique. This methodology allows much higher grid densities to be used near typical fronts than current simulators. We improved the upscaling strategy on these grids, and derived an effective way to generate upscaled permeabilities that preserve local fluxes. We have started more in-depth research into splitting methods for stiff PDEs such as those found in in-situ combustion simulation. We will report on these new developments extensively in the next quarterly report. This quarterly report, we focus on experimental work.

On the experimental side, we have fleshed out a mechanism of improved in-situ combustion with aqueous metallic salts using scanning electron microscopy (SEM) and the transport phenomenon of such additives through porous media. Based on the observations from SEM analysis, we propose cation exchange of metallic salts with clay as a mechanism to create activated sites that enhance combustion reactions between oil and oxygen. Moreover, the empirical ranking of the success of metallic ions as catalytic additives for in-situ combustion is interpreted as originating from three factors: cation replacing power, distribution of metallic additive adsorption sites, and cation catalytic power for oxidation and cracking of hydrocarbon. 


\title{
Table of Contents
}

\author{
List of graphical materials
}

1. Introduction

2. Executive Summary

2.1. Personnel

2.2. Important accomplishments

3. Experimental

4. Results and discussion

5. Conclusion

\section{References}

\section{List of graphical materials}

Figure 1. SEM analysis of the mixture of sand, silica powder, and $\mathrm{Sn}^{2+}$ additive. (a) SEM image from the signal of secondary electrons; (b) SEM image from the combined signals of secondary and backscattered electrons; (c) compositional analysis from EDAX.

Figure 2. Statistical analysis of the distribution of metallic additive deposition within the mixture of sand, clay and $\mathrm{Fe}^{3+}$ additive: (a) locations of sampling points and (b) four classes of $\mathrm{Fe}$ signal.

Figure 3. Schematic representation of experimental procedure.

Figure 4. Temperature response for kinetics cell, ramped temperature oxidation of the residues following various solvent injections at 40 psi backpressure.

Figure 5. Experimental setup for transport of metallic additives through porous media 


\section{Introduction}

In-situ combustion, or air injection, is the process of injecting oxygen into oil reservoirs to oxidize the heaviest components of the crude oil and enhance oil recovery through the heat and pressure produced. The emphasis of this work is to study and model numerically in situ combustion processes. The ultimate objectives are to provide a working accurate, parallel in situ combustion numerical simulator and to better understand the in-situ combustion process when using metallic additives and/or solvents combined with in situ combustion. For this purpose, experimental, analytical and numerical studies are conducted.

This report presents results of the second quarter of the second year of this project. In this report we focus on the experimental program. In the next quarterly report we will extensively discuss our recent numerical progress for which we are currently conducting numerical experiments. 


\section{Executive Summary}

\subsection{Personnel}

Current personnel include Prof. Margot Gerritsen (PI), Prof. Tony Kovscek (Co-PI), Dr. Louis Castanier (Technical manager), Dr. Jonas Nilsson (postdoctoral fellow), Mr. Rami Younis (PhD student), and Mr. Qing Chen (MSc student). Mr. Jean Cristofari (MSc student) is also working on the project, albeit paid from departmental sources.

\subsection{Important accomplishments}

\subsubsection{Numerical solvers.}

In the previous quarterly reports, we described the Cartesian Cell-based Adaptively Refined (CCAR) grids and appropriate finite volume methods for these grids that we are developing for our in-situ combustion simulator. CCAR grids allow very aggressive refinement near important features, such as the combustion front, and are efficient because of their underlying Cartesian structure. In the last quarter, we included an extensive discussion of our novel multi-level upscaling methodology for CCAR grids. At that time, we focused primarily on traditional permeability upscaling. However, on uniform Cartesian grids, transmissibility upscaling is generally shown to lead to more accurate global flow results than permeability upscaling. In transmissibility upscaling, the transmissibilities at the faces of the coarse cells are directly upscaled from the integrated fluxes on the underlying fine scale. This quarter we derived an accurate method to upscale permeabilities that preserve fluxes and lead to global coarse flows of the same accuracy as those obtained using transmissibility upscaling. We are currently in the process of compiling numerical evidence and will report on this in detail in the next quarterly reports.

We have also continued our research into the design of appropriate splitting methods for stiff systems of ODEs resulting from the ISC process. Our main focus this quarter however is on the experimental work.

\subsubsection{Experimental in-situ combustion}

The experimental program is focused on the proof of concept for (i) water-soluble metallic salts to improve fuel lay down and enhancement of combustion performance as well as (ii) a new recovery concept that combines cyclic solvent injection and in-situ combustion to remove any solid precipitation resulting from the solvent.

For a detailed description of our experimental set-up and procedures followed in the experiments, please see section 3.

\section{Metallic Additives}

Previous reports detailed experiments in a kinetics cell to measure the rates and kinetics of combustion in the presence and absence of metallic additives. Water-soluble, metallic additives such as these improve combustion by affecting cracking, low temperature oxidation, and pyrolysis reactions thereby improving fuel laydown. The mechanism of catalysis by metallic additives is not yet known. It is our working hypothesis that the cationic metals ion exchange 
with ions residing in the clay to create an activated site that acts in a manner analogous to a heterogeneous catalyst.

Our recent work in this area has been to flesh out a mechanism of improved in-situ combustion with aqueous metallic salts using scanning electron microscopy (SEM) and the transport phenomenon of such additives through porous media. The samples with and without metallic additives used for combustion cell experiments are examined with SEM for any textural or compositional changes. Based on the observations from SEM analysis, we propose cation exchange of metallic salts with clay as a mechanism to create activated sites that enhance combustion reactions between oil and oxygen. Moreover, the empirical ranking of the success of metallic ions as catalytic additives for in-situ combustion is interpreted as originating from three factors: cation replacing power (i.e. a Hofmeister series (Grimm, 1968)), distribution of metallic additive adsorption sites, and cation catalytic power for oxidation and cracking of hydrocarbon.

\section{Transport experiments}

We started an experimental investigation of the transport of aqueous metallic additives. The concentration of metallic additive found on surfaces in each portion of the pack was quite low. This indicates that metallic additives such as tin chloride are mobile and do not bind irreversibly to solid surfaces. Further work is necessary, of course, but these preliminary results suggest that it should be quite possible to place metallic additives within the reservoir via a slug of additive dissolved in water.

\section{Scanning Electron Microscope}

The SEM examination of these samples, as given in past reports and elsewhere (He et al., 2005) has yielded the following observations. First, the introduction of metallic catalyst ions has not changed remarkably the morphology of the clay within mixtures of sand and clay. Various sand, clay mixtures metallic additive $\left(\mathrm{Sn}^{2+}\right.$ and $\left.\mathrm{Cu}^{2+}\right)$ mixtures have been examined and similar results have been obtained, indicating that the presence of aqueous metallic additives does not change clay morphology. Second, metallic additives are associated with both clay and fine-grained silica powder providing a possible explanation for the catalytic effect of additives in prior kinetics cell experiments that did not include clay, but had fine-grained silica powder, in the mixture (He et al., 2005).

The SEM imaging has also provided better information about spatial distribution of metallic ions on the solid substrate. The general tendency of ion deposition was studied by comparing images constructed from the secondary electron signal and the backscattered electron signal, where the former provides the morphological information while the latter shows the elemental information. Figure 1 presents two such images taken at the exact same location of the sand-silica-tin chloride system at a magnification of 650x. The bright areas in the backscattered electron image (Figure 1(b)) indicate the presence of the element with large atomic weight that is tin. Figure 1(c) presents the result of compositional analysis at the site defined by a square in the image. A strong tin signal is observed in the spectrum, verifying the abundance of deposited tin within the bright area. By carefully comparing the two SEM images, it is found that tin deposits mostly on the surface of silica powder rather than the large sand grains. Because silica powder has the same chemical composition as sand grains but more specific surface area, the preference of tin deposition for silica powder suggests that the ion deposition is likely proportional to the surface area of the solid substrate, which is expected. 
The distribution of ion deposition has also been checked within the system of sand, kaolinite, and ferrous nitrate. Due to the sensitivity of backscattered electron signal to surface charging and poor conductivity of clay surface, however, the backscattered electron mode does not provide high quality images of clay as obtained for the silica powder system. Thus, a statistical method based on the compositional spectrum analysis was employed to analyze the system with kaolinite. The analysis procedure is as follows. A region with dimensions of about $300 \mu \mathrm{m}$ by $200 \mu \mathrm{m}$, for example, is defined. Figure 2(a), is randomly taken as a sampling area, where many sampling points distributed uniformly are chosen for the compositional analysis. Because of the different elemental compositions between sand grains ( $\mathrm{Si}, \mathrm{O})$ and clay $(\mathrm{Si}, \mathrm{O}, \mathrm{Al})$, it is easy to determine whether a sampling point is upon the surface of sand grains or clay from the spectrum analysis of that point. Accordingly, the sampling points are classified into two groups, sand and clay. Within each group, the presence of iron (Fe) at each sampling site can be qualitatively indicated by the strength of the iron signal in the spectrum obtained at the corresponding location. Four levels of the iron spectral signal-none, weak, normal, and strong, as shown in Figure 2(b), are set for the statistic analysis and the number of sampling points is counted accordingly. The procedure is then repeated for other different regions.

Table 1 summarizes the statistical results for three different regions of sample surfaces. It is seen that iron deposition is mostly associated with clay. For example, at Region \#2, iron deposition is found at more than half of sampling locations on the clay surface, however, almost all sampling locations that are on the surface of sand grains show no iron signal at all. This result is consistent with the observation found in the mixture of sand, silica powder and tin chloride. The preference of ion deposition on clay as well as the local ion deposition observed above provides the evidence of the cation exchange between metallic additives and ion residing on clay.

Table 1 Statistics of sampling sites presenting iron signal from compositional analysis.

\begin{tabular}{c|c|c|c|c|c}
\hline \multirow{2}{*}{ region } & \multirow{2}{*}{ substrate } & \multicolumn{4}{|c}{ signal of iron (Fe) } \\
\cline { 3 - 6 } & & none & weak & normal & strong \\
\hline \multirow{2}{*}{$\# 1$} & clay & 5 & 7 & 4 & 3 \\
\cline { 2 - 6 } & sand & 10 & 0 & 0 & 0 \\
\hline \multirow{2}{*}{$\# 2$} & clay & 11 & 11 & 2 & 1 \\
\cline { 2 - 6 } & sand & 19 & 1 & 0 & 0 \\
\hline \multirow{2}{*}{$\# 3$} & clay & 5 & 13 & 5 & 3 \\
\cline { 2 - 6 } & sand & 6 & 1 & 0 & 0 \\
\hline
\end{tabular}

\section{Solvent-Combustion Process}

We have proposed cyclic injection of solvents to upgrade oil in situ, followed by in-situ combustion of a small part of the reservoir to increase the temperature near well bore and also to clean the well bore region of all residues left by the solvents. Both solvent injection and in-situ combustion are technically effective in a variety of reservoirs. The combination of the two methods has, however, never been tried to our knowledge.

This study probes the feasibility of the cyclic solvent process using conceptually simple laboratory experiments as well as the in-situ upgrading possibilities of the method as shown schematically in Figure 3. First, the solvent injection extracts light components of the crude oil and precipitates asphaltenes. The upgraded oil is produced from the same well where solvent was 
injected. Then, in-situ combustion burns these flocks of asphaltenes and cracks medium size molecules. Table 2 summarizes the experiments run to date.

Table 2: Experimental summary.

\begin{tabular}{|c|l|c|}
\hline Test & \multicolumn{1}{|c|}{ Experiment } & Comments \\
\hline Test 1 & "Pure" control run, no solvent injection & \\
\hline Test 2 & $\sim 50 \mathrm{ml}$ of C5 injected at atmospheric pressure then combustion & \\
\hline Test 3 & $\begin{array}{l}\sim 100 \mathrm{ml} \text { of kerosene injected at atmospheric pressure then } \\
\text { combustion }\end{array}$ & Failed (Plug) \\
\hline Test 4 & $100 \mathrm{ml}$ of C5 injected at 40 psi then combustion & \\
\hline Test 5 & $50 \mathrm{ml}$ of C5 injected at 40 psi then combustion & Failed (Plug) \\
\hline Test 6 & $100 \mathrm{ml}$ of kerosene injected at 40 psi then combustion & \\
\hline Test 7 & $25 \mathrm{ml}$ of kerosene injected at 40 psi then combustion & \\
\hline Test 8 & $100 \mathrm{ml}$ of C10 injected at 40 psi then combustion & \\
\hline Test 9 & $100 \mathrm{ml}$ of C5 injected at 40 psi then combustion & \\
\hline
\end{tabular}

Figure 4 presents representative results from our experiments. The oil is a $10.5^{\circ} \mathrm{API}$ crude from Hamaca, Venezuela. Three different solvents, kerosene, n-decane, and pentane, were injected into a mixture of sand, clay, crude oil, and water in the kinetics cell. Solvent was then injected to displace the heavy crude and partially deasphalt the oil. The material in the sand pack was then subjected to ramped temperature oxidation to measure if the remaining crude oil fractions provided sufficient fuel for combustion. For reference, control run results are also given. When pentane is used as a solvent, the combustion reactions are more exothermic. The temperature increases by $225^{\circ} \mathrm{C}$ as combustion reactions start. In the case of kerosene or decane, the increase in temperature is smaller: it is insignificant in the case of kerosene and temperature rises only by $150^{\circ} \mathrm{C}$ in the case of decane. Temperature increases as fuel is burned and the more exothermic the reaction, the more fuel is burned and by inference more fuel has been previously deposited. Pentane has lead to large fuel deposition for the same amount of sand/oil mixture at the beginning and more exothermic HTO reactions.

Pentane generally dissolves resins but not asphaltenes. Therefore, we assume that a greater amount of asphaltenes precipitate when pentane is injected and thus more fuel is deposited in the kinetic cell. Asphaltenes are slightly soluble in decane and kerosene and thus they precipitate less when decane or kerosene are injected. Pentane extracts more light components and leaves more heavy components in the kinetic cell whereas kerosene and decane extract more heavy components than pentane.

Our work on proving up the feasibility of the cyclic solvent injection and combustion process continues. We plan to repeat the same experiments on heavy oil from the West Sak field, in Alaska. It is lighter than the Hamaca crude oil used in the above experiments. Furthermore, insitu combustion is attractive as air injection wells do not incur significant heat losses to the overburden and gaseous emissions remain in the reservoir. Heat losses are of especial concern in Alaska due to large columns of permafrost around the well bore.

We are also planning to do a tube run: it is similar to the kinetic cell experiment except that the tube is one meter long. We will then be able to measure the properties from the recovered oil (density and viscosity) and to estimate quantitatively the upgrading. 


\section{Experimental}

\section{Sample preparation for metallic additives experiments}

Various mixtures that are representative of the solid substrates and ionic environment of combustion experiments are prepared for both transport experiments and SEM examination. Those mixtures are mainly composed of $94 \%$ sand (finer than 100 mesh) and $6 \%$ clay (kaolin powder, J.T. Baker Chemicals) in weight that are thoroughly mixed with either water or an aqueous solution containing an additive. For comparison, kaolin powder, that has chemically active surfaces, is substituted by silica powder ( 240 mesh, Fisher Scientific), a surface-inert material, in the preparation of some sand mixtures due to their large specific surface area. Three typical additives studied in this work are $\mathrm{Fe}^{3+}, \mathrm{Sn}^{2+}$, and $\mathrm{Cu}^{2+}$ provided in the forms of ferric nitrate $\left(\mathrm{Fe}\left(\mathrm{NO}_{3}\right)_{3} \cdot 9 \mathrm{H}_{2} \mathrm{O}\right.$, Baker \& Adamson Chemicals), tin chloride $\left(\mathrm{SnCl}_{2} \cdot 2 \mathrm{H}_{2} \mathrm{O}\right.$, J.T. Baker Chemicals), and copper chloride $\left(\mathrm{CuCl}_{2} \cdot 4 \mathrm{H}_{2} \mathrm{O}\right.$, Baker \& Adamson Chemicals), respectively. The molar concentration of those additives, if added into the mixture, is fixed approximately at 2 mol\% to be consistent with the previous experiments (Shallcross et al., 1991; He et al., 2005).

\section{Set-up for the transport experiments}

The experimental setup for the study of the transport of aqueous metallic additives through porous media is shown in Figure 5. A beaker containing the flooding liquid is connected to a plastic tube with a diameter of $1 / 2$ ” and a length of 12 ” via a high precision syringe pump (Teledyne Isco Inc., Lincoln, NE, Model 500D). The syringe pump provides constant flow rates ranging from 0.001 to $204 \mathrm{ml} / \mathrm{min}$ with an accuracy of $\pm 5 \%$. The tube is packed with the sandclay mixture prepared as described in the previous subsection. During the sand packing, care is taken to ensure a relatively even distribution of porosity and permeability along the tube. A fine stainless steel screen is glued to both the inlet and outlet of the tube to prevent the solid from coming out of the tube. For better displacement, the tube is placed vertically and the flooding liquid is injected through its bottom end. Another beaker is used to collect the fluid produced at the upper end of the tube for compositional analysis.

The tube was fully packed with a sand-clay mixture and placed vertically. Tin chloride additive was present only in the bottom half of the tube at a concentration of $2 \mathrm{~mol} \%$. After tightening the end plugs and connecting fittings, pure water was injected from the bottom inlet of the tube and was forced to flood the section of the pack with $\mathrm{Sn}^{2+}$ and then the section of the pack without $\mathrm{Sn}^{2+}$. The injection rate was set to $0.1 \mathrm{ml} / \mathrm{min}$, resulting in a front velocity around $1 \mathrm{~m} / \mathrm{d}$. The experiment was terminated after injection of $1.5 \mathrm{PV}$. The sand-clay mixture was then carefully pushed out from the tube with the help of a piston, such that the relative position of the sample originally packed in the tube remained, which allows sampling along the tube for SEM analysis.

\section{Scanning electron microscope}

Microscopic imaging and elemental analysis are employed to evaluate any textural or compositional changes in the sand-clay mixture upon addition of metallic additive. A JEOL JSM-500LV SEM system is used to collect digital images. The system captures secondary electrons as well as back-scattered electrons. In addition, an EDAX Sapphire $\mathrm{Si}(\mathrm{Li})$ energy dispersive system (EDS) with GENESIS software allows elemental analysis and mineral identification. For SEM analysis, samples are prepared as grain mounts. Sand-clay mixtures are placed on double sided adhesive carbon tabs and mounted on cylindrical aluminum SEM mounts. Grain mounts are coated with a monolayer of gold or a gold-palladium mixture to provide a 
conductive coating on the surface of the sample. This reduces possible problems with surface charging that is common during SEM analysis.

\section{$\underline{\text { Solvent-Combustion Process }}$}

Alternate slugs of solvent and air are injected and allowed to soak. Production is after each slug. The process is repeated until economic limit is reached. A typical experimental run begins by injecting solvent through an oil-water-sand mixture to precipitate the asphaltenes and recover the light ends. Then, air flows through the mixture while heating: this technique is often referred to as the "ramped temperature oxidation" (RTO) experiment. The purpose is to study the oxidation behavior. We start by packing about 35 grams of the sand/oil mixture into a kinetic cell placed vertically to minimize the effect of gravity. The kinetic cell is composed of two cups housed in the kinetic cell, both with perforated bottoms. The lower cup is filled with clean sand and distributes uniformly the gas feed. The upper cup is packed with the oil-water-sand mixture and is right on the top of the other cup. The kinetic cell is connected at its end by a back pressure regulator to pressurize the cell at $40 \mathrm{psi}$. Gas feed is preheated in a coil tubing before it enters the cell at its lower end. After measuring the desired volume of solvent, we inject it at the top of the cell with nitrogen at atmospheric temperature and recover the upgraded oil. We then inject air through the kinetic cell placed in a furnace and temperature is programmed to increase linearly with time $\left(100^{\circ} \mathrm{C}\right.$ per hour) up to $650^{\circ} \mathrm{C}$. Air is supplied by high pressure cylinders. The pressure at the entrance of the cell is about 120 psi and gas flows out at 90 psi, maintained by a pressure regulator. Gas flows before and after the cell are measured by separate electronic mass flow controllers. Concentrations of $\mathrm{O}_{2}, \mathrm{CO}, \mathrm{CO}_{2}$, and $\mathrm{CH}_{4}$ from the effluent gas are measured by a gas analyzer that is previously calibrated with air, nitrogen and gas mixtures $\left(10 \%\right.$ of $\mathrm{CO}_{2}$ and $10 \%$ of $\mathrm{CH}_{4}$ ). Temperature profile is also recorded and data is collected approximately at one minute intervals. When $650^{\circ} \mathrm{C}$ is reached, the system is shut down and is left to cool to room temperature.

\section{Results and discussion}

This report covers the sixth quarter of our research grant. The quarter was used primarily to further design the computational algorithms, with increased emphasis on the three-dimensional simulator, and to continue our experimental work. We have made very good progress in these areas again this quarter. In this report we focus almost exclusively on the experimental results. Next quarter the emphasis will be on the numerical framework. Three papers on our work were presented at the Society of Petroleum Engineers Reservoir Simulation Symposium and the Society of Petroleum Engineers Western Regional Meeting. They are attached to this report.

\section{Summary and discussion of experimental findings}

\section{Metallic additives}

Based on the observations from the SEM analysis, we suggest that the cation exchange of metallic salts with clay acts as a mechanism to create activated sites. We have also found good indications that the empirical ranking of the success of metallic ions as catalytic additives originates from three factors: cation replacing power (i.e. a Hofmeister series (Grimm, 1968)), distribution of metallic additive adsorption sites, and cation catalytic power for oxidation and cracking of hydrocarbon. 


\section{Transport experiments}

Because the concentration of metallic additive found on surfaces was relatively low we believe that metallic additives such as tin chloride do not bind irreversibly to solid surfaces. This is an encouraging result. It suggests that it should be possible to place metallic additives within the reservoir via a slug of additive dissolved in water.

\section{Scanning Electron Microscope}

The SEM analysis has lead to the following important observations:

- The introduction of metallic catalyst ions has little effect on the morphology of the clay within mixtures of sand and clay.

- Tin deposits mostly on the surface of silica powder rather than the large sand grains. This suggests that the ion deposition is proportional to the surface area of the solid substrate.

- Iron deposition is mostly associated with clay.

The SEM analysis has improved our understanding of the deposition of metallic additives. The analysis will be very important in analyzing effectiveness of placement of metallic additives via a slug dissolved in water.

\section{Solvent-Combustion Process}

When pentane is used as a solvent, the combustion reactions are more exothermic. For kerosene the temperature rise is insignificant, and for decane smaller than for pentane. Because pentane generally dissolves resins but not asphaltenes, we suggest that a greater amount of asphaltenes precipitate when pentane is injected and thus more fuel is deposited in the kinetic cell. This would explain the more exothermic reactions. Asphaltenes are slightly soluble in decane and kerosene and thus they precipitate less when these solvents are injected.

\section{Conclusions}

We will continue to focus on understanding how the additives work during combustion. Our work confirms the working hypothesis that metallic ions create activated sites within the solid substrate where combustion processes are enhanced. We have found an appropriate indicator (CHIRR) that can be used to rank metallic additives. This indicator is in agreement with existing experimental data. The current results are a step forward to improving the design of in-situ combustion processes using metallic additives.

The next steps include an in-depth investigation of the transport of metallic additives using aqueous solutions. This is a very important investigation as it will help determine whether metallic additives are of important practical use.

Also, we will continue our work on proving up the feasibility of the cyclic solvent injection and combustion process continues. We will first repeat the same experiments as reported here on heavy oil from the West Sak field, in Alaska. It is lighter than the Hamaca crude oil used in the above experiments. Using a tube run in addition to a kinetic cell experiment will allow us to 
measure the properties from the recovered oil (density and viscosity) and to estimate quantitatively the upgrading.

\section{References}

Shallcross, D.C., Rios, C.F. De Los, Castanier, L.M. 1991. "Modifying In-Situ Combustion Performance by the Use of Water-Soluble Additives”, SP

He, B.: 2004. "The Effect of Metallic Salt Additives on In-Situ Combustion Performance”, M.S. Report Stanford University. Online at http://ekofisk.stanford.edu/pereports/web /default.htm

Grim, R. E.: Clay Mineralogy, McGraw Hill: New York, 1968.

He, B., Chen, Q., Castanier, L.M. and Kovscek, A.R., "Improved In-Situ Combustion Performance with Metallic Salt Additives," SPE 93901, Proceedings of the SPE Western Regional Meeting, Irvine, CA, Mar 30-Apr 1, 2005 (included with this quarterly report)

Dabbous, M.K. and Fulton, P.F., 1972. "Low Temperature Oxidation Kinetics and Effects on the In-Situ Combustion Process," paper SPE 4143 presented at SPE-AIME $47^{\text {th }}$ Annual Fall Meeting, San Antonio, Tex., Oct. 8-11.

Fassihi, M.R., Brigham, W.E., and Ramey, H.H., 1984. "Reaction Kinetics of In-Situ Combustion: Part 1—Observations,” SPEJ (Aug.), 399-416. 


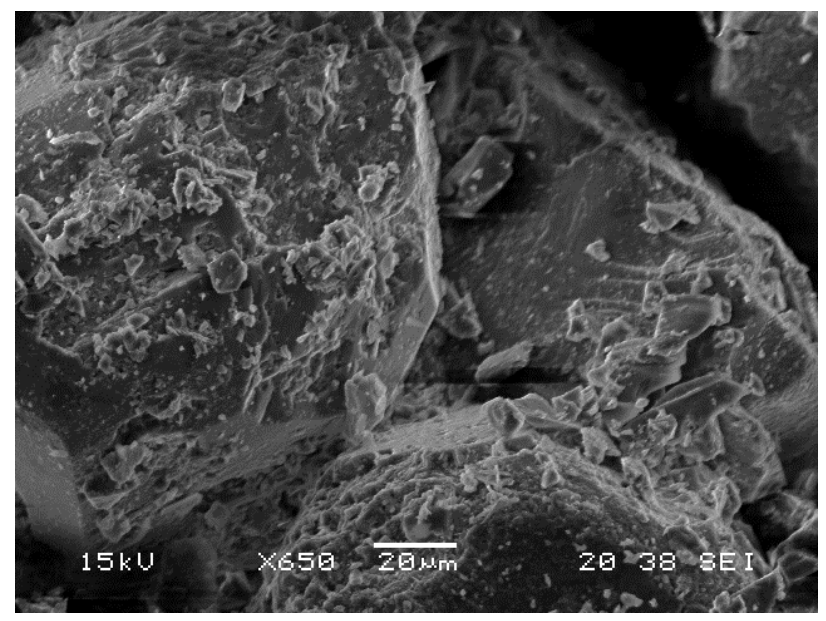

(a)

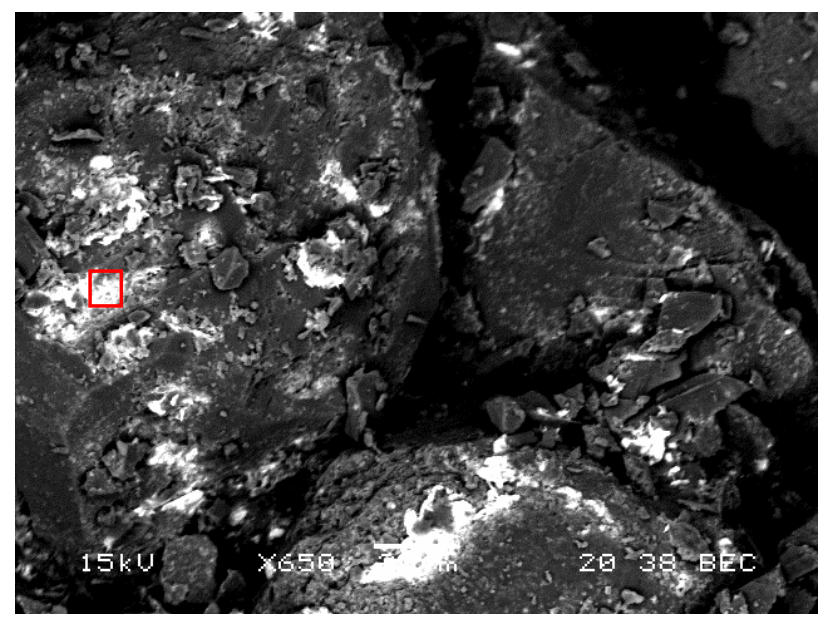

(b)

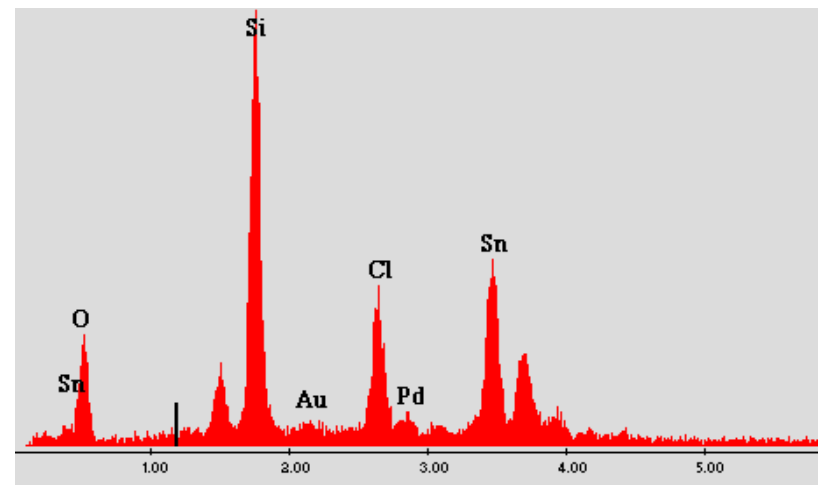

(c)

Figure 1: SEM analysis of the mixture of sand, silica powder, and $\mathrm{Sn}^{2+}$ additive. (a) SEM image from the signal of secondary electrons; (b) SEM image from the combined signals of secondary and backscattered electrons; (c) compositional analysis from EDAX. 


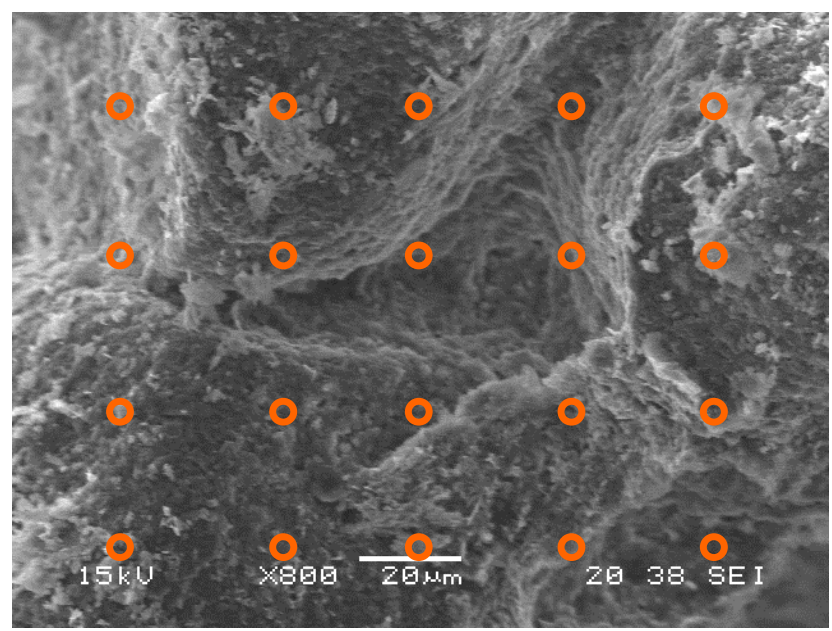

(a)
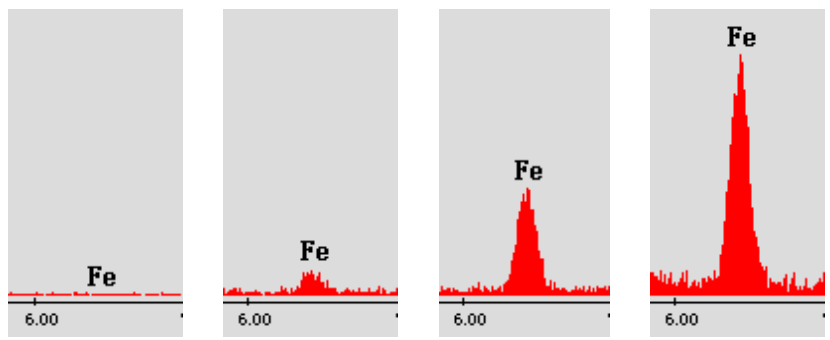

(b)

Figure 2. Statistical analysis of the distribution of metallic additive deposition within the mixture of sand, clay and $\mathrm{Fe}^{3+}$ additive: (a) locations of sampling points and (b) four classes of Fe signal. 


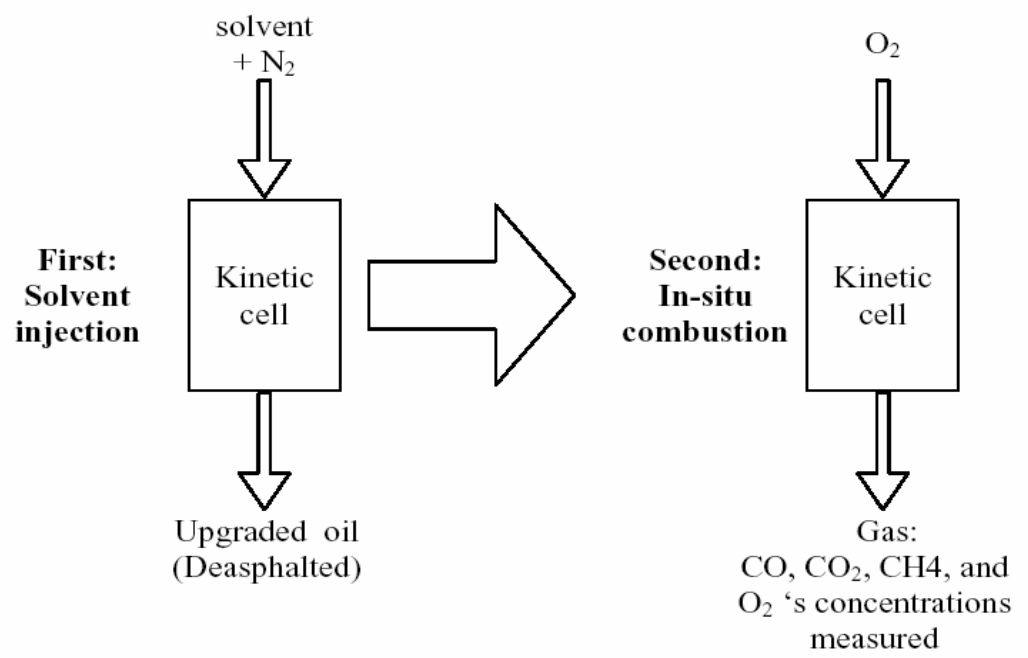

Figure 3. Schematic representation of experimental procedure. 


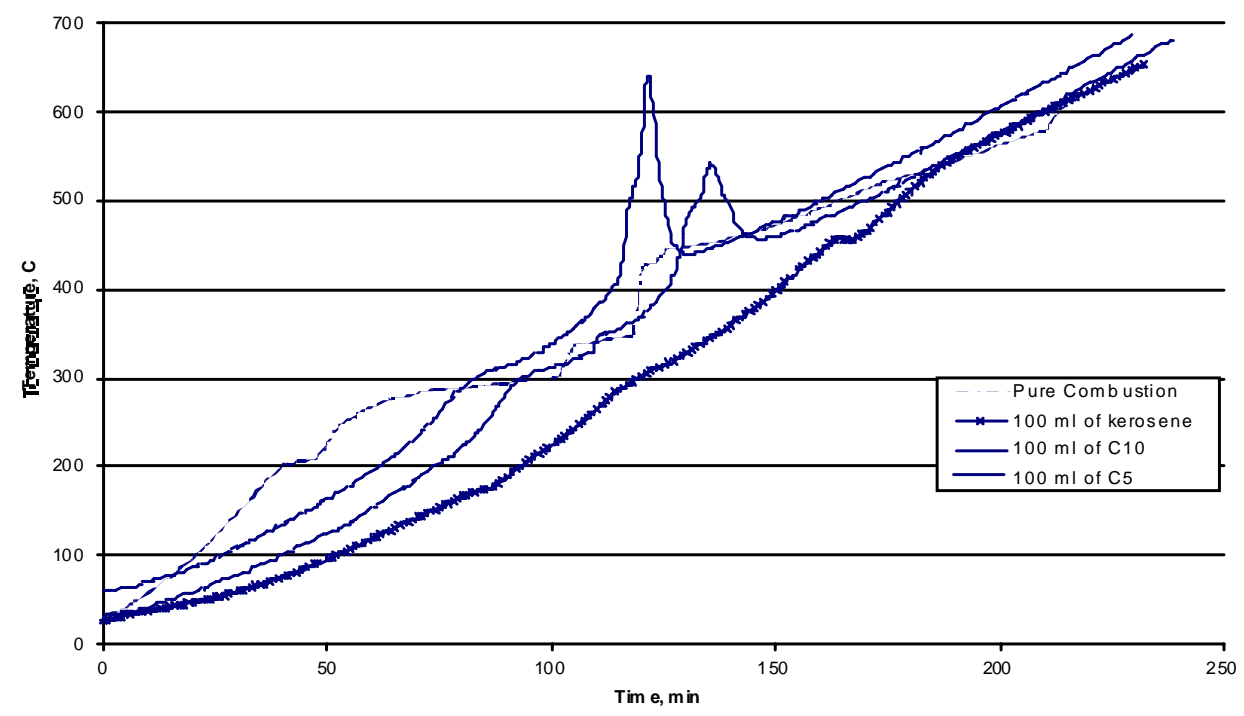

Figure 4. Temperature response for kinetics cell, ramped temperature oxidation of the residues following various solvent injections at 40 psi backpressure. 


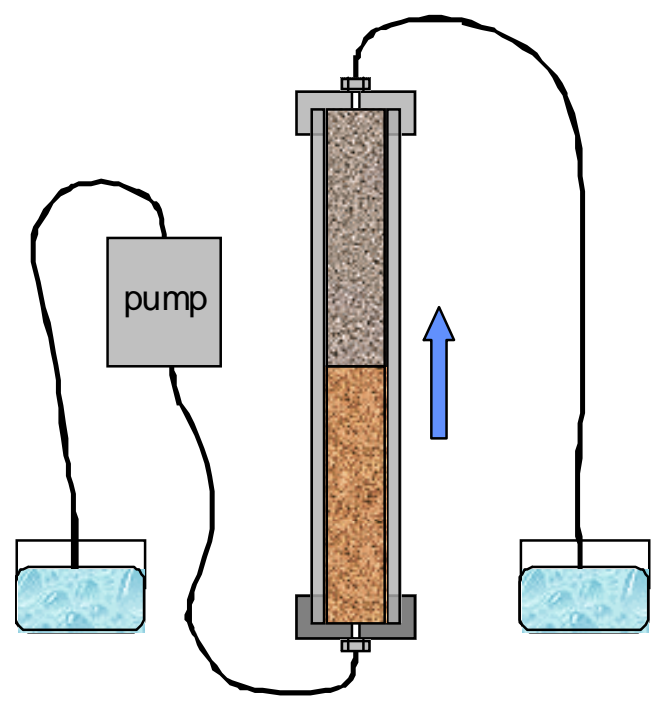

Figure 5. Experimental setup for transport of metallic additives through porous media 